\title{
FREIRE COMO AUTOR INTERNACIONAL: PEDAGOGIA DO OPRIMIDO EM LÍNGUA INGLESA PUBLICADA 50 ANOS ATRÁS
}

\author{
MARCONDES, Maria Inês*
}

\begin{abstract}
RESUMO
O livro Pedagogia do Oprimido (PO) é considerado um dos dez livros mais importantes de currículo do século XX por indicação da Associação Americana pelo Desenvolvimento dos Estudos Curriculares (American Association for the Advancement of Curriculum StudiesAAACS). Para compreender Pedagogia do Oprimido, que teve sua primeira publicação em inglês em 1970, não se pode deixar de ler Pedagogia da Esperança (1992), livro em que o próprio Freire faz uma narrativa reflexiva sobre sua própria vida. As questões de nossa pesquisa são: Por que Paulo Freire é considerado um autor internacional? Como ele influenciou o contexto internacional dos estudos curriculares, inicialmente com a publicação da obra PO em língua inglesa, há cinqüenta anos atrás. A pesquisa mostra que a experiência internacional decorrente do exílio imposto a Freire traz uma nova dimensão para sua obra. Sua permanência no Chile, tendo contato com sindicalistas e trabalhadores, redefiniu sua tese, Educação e Atualidade Brasileira, publicada como livro intitulado Educação como Prática da Liberdade e ampliou sua reflexão para a finalização do texto da Pedagogia do Oprimido, que termina de rever no Chile. Sua permanência nos Estados Unidos em contato permanente com trabalhadores e intelectuais, assim como sua experiência no Conselho Mundial de Igrejas, possibilitaram a Freire ter contato com outros países e realidades diferentes. Nessas constantes viagens, Freire é influenciado pelo contexto internacional assim como influencia muitos intelectuais entre eles, vários educadores críticos do campo dos estudos curriculares.
\end{abstract}

PALAVRAS-CHAVE: Paulo Freire. Influência Internacional. Estudos Curriculares.

*Pontifícia Universidade Católica do Rio de Janeiro, Programa de Pós-Graduação em Educação. Rio de Janeiro, Rio de Janeiro, Brasil. E-mail: mim@ @uc-rio.br. OrCid: https://orcid.org/0000-0002-0973-9405 


\title{
FREIRE AS AN INTERNATIONAL AUTHOR: \\ PEDAGOGY OF THE OPPRESSED IN ENGLISH LANGUAGE PUBLISHED \\ 50 YEARS AGO
}

\section{MARCONDES, Maria Inês*}

\begin{abstract}
The book Pedagogy of the Oppressed (PO) is one of the major books of the 20th century according to the American Association for the Advancement of Curriculum Studies (AAACS). To better understand Pedagogy of the Oppressed, that had its first in English language in 1970, we cannot avoid to read Pedagogy of Hope (1992), the book in which Freire made a reflective narrative about his own life. Our research questions are: Why is Paulo Freire an international author? How he influenced the international context of curriculum studies, initially with the publication of Pedagogy of the Oppressed in English language fifty years ago. Our research findings show that the international experience of exile imposed on Freire brings a new dimension to his work. His stay in Chile, having made contact with unions and workers, redefined his thesis Educação e Atualidade Brasileira, published in a book edition in English as Education and the Practice of Freedom. Freire amplifies his reflection and conclusions to finish the original text of Pedagogy of the Oppressed in Chile. Freire's stay in Chile working with workers and intellectuals, such as his experience in World Council of Churches made possible to him to contact other countries and different realities. In his travels Freire is influenced by the international context as influencing many intellectuals among them, several critical educators of curriculum studies field.
\end{abstract}

KEYWORDS: Paulo Freire. International Influence. Curriculum Studies.

* Pontifical Catholic University of Rio de Janeiro, Graduate Program in Education. Rio de Janeiro, Brazil.

E-mail: mim@puc-rio.br. OrCid: https://orcid.org/0000-0002-0973-9405 


\section{INTRODUÇÃO}

O livro Pedagogia do Oprimido (PO) foi considerado um dos dez livros mais importantes da área dos estudos curriculares do século XX pela American Association for the Advancement of Curriculum Studies (AAACS). Para compreender Pedagogia do Oprimido não se pode deixar de ler também a obra Pedagogia da Esperança, livro em que o próprio Freire faz uma narrativa autobiográfica reflexiva sobre sua própria vida, apresentando o seu percurso, suas escolhas e os desdobramentos das decisões tomadas durante sua vida. A pesquisa então tem como indagações básicas: Por que Paulo Freire é considerado um autor internacional? Como ele influenciou o contexto internacional de estudos curriculares, inicialmente com a publicação da PO?

O texto está organizado da seguinte forma: inicialmente, explicamos como Freire, a partir da experiência do exílio, vai alterando seu projeto de vida e de trabalho no Brasil adquirindo com viagens e contatos com trabalhadores e pesquisadores de outros contextos uma perspectiva internacional. Em seguida, apresentamos como, a partir da publicação de seus escritos em língua inglesa, como artigos na Harvard Educational Review, e da obra Pedagogia do Oprimido em tradução para o inglês, torna-se um autor internacional. Nas considerações finais, retomamos as principais ideias discutidas ao longo texto. A questão metodológica de construção deste artigo se baseou inicialmente na leitura de textos do próprio Freire, seguida de leituras complementares buscando seu percurso relativo à sua internacionalização.

\section{ADQUIRINDO UMA PERSPECTIVA INTERNACIONAL}

Nessa seção, mostraremos como Paulo Freire, a partir de suas experiências de vida e de trabalho, recusa-se a viver de memórias no exílio, assumindo um papel de protagonista e ator de sua história, ainda que não tivesse sido seu desejo e projeto inicial de vida deixar sua terra, seu país. 


\section{e-Curriculum}

\subsection{Antecedentes da Pedagogia do Oprimido: Freire, empobrecimento de sua família, mudança de carreira, casamento, influências prévias em seu trabalho}

Temos acesso à história de vida de Freire a partir de sua própria obra, que consideramos como um relato reflexivo de sua vida contada por meio de exemplos encontrados basicamente na obra Pedagogia da Esperança, em que Freire expõe vários incidentes de seu percurso e explica aspectos sobre a produção e publicação da sua obra mais marcante, Pedagogia do Oprimido. Nessa narrativa pessoal, a identidade de Freire como recifense, pernambucano, brasileiro, latino-americano e posteriormente "homem do mundo" vai se constituindo pelo seu contato com outras pessoas e outros contextos. Suas preocupações com as questões sociais, desde o início de sua vida, os estudos firmando seu pensamento nas bases teóricas da fenomenologia e do marxismo colocaram Freire como intelectual de fronteira, pós-colonial, segundo Giroux (1995).

Inicialmente, Freire não tinha ideia de sair do Brasil e projetar-se no cenário internacional. Sua saída foi consequência da situação política, decorrente do Golpe de Estado de 1964, que levou à sua prisão e a ser interrogado diversas vezes pelo Regime Militar. Entretanto, Freire foi capaz de transformar a experiência do exílio em uma oportunidade de crescimento pessoal e intelectual. Nessa perspectiva, vivendo fora do país, Freire não se conforma em viver do passado, apenas em função de suas memórias, mas usa sua identidade de brasileiro, nordestino, educador, para "ler" os novos contextos em que vive e a redimensionar seu projeto de vida. Ao aproveitar as oportunidades que apareciam em seu percurso, torna-se autor, educador e pessoa internacionalmente conhecida, com grande projeção na área dos estudos curriculares e da pedagogia crítica.

\subsection{As primeiras dificuldades: empobrecimento da família, mudança de carreira profissional e casamento com Elza}

Paulo Freire era um homem jovem em 1940. Apesar de viver em um país que estava começando a sonhar com um desenvolvimento social e econômico, nasceu e cresceu em uma região do país subdesenvolvida com muitas desigualdades sociais - o Nordeste. Seus pais não eram os mais pobres da região, mas com a Grande Depressão e a doença de seu pai a família 
foi forçada a mudar-se de Recife para uma cidade próxima, Jaboatão, onde o custo de vida era mais baixo. O falecimento do pai de Freire quando ele tinha apenas 13 anos deixou a família em situação difícil. Mais tarde ele relembrou a experiência da fome durante aqueles anos, assim como a amizade que fez com pessoas da classe trabalhadora.

Com vinte anos, Freire entra para a Universidade do Recife para cursar Direito. Sua carreira, entretanto, iria seguir um caminho diferente. Ensinava Português no ensino médio e continuou ensinando depois de formado. Freire logo abandonou sua carreira de advogado quando aceitou sua primeira causa - um caso de despejo, pois se sentiu muito angustiado e não conseguiu processar o indivíduo que estava para ser despejado. Viu, então, a partir desse episódio, que não tinha condições de trabalhar como advogado. Sua esposa, Elza, apoiou essa decisão que transformaria radicalmente seu percurso de vida. Foi então trabalhar no Serviço Social de Indústria em Pernambuco, uma agência para a melhoria das classes populares criada em julho de 1946. Neste emprego passou também por experiências que foram fortalecendo o desejo de trabalhar com as classes menos favorecidas.

O casamento com a educadora Elza Maia Costa de Oliveira, em 1944, foi um fato marcante em sua vida. Em muitas passagens na obra Pedagogia da Esperança, Freire ressalta a importância de Elza para o desenvolvimento de seu trabalho. Ela não foi apenas esposa de Freire e mãe de seus filhos, foi também a grande companheira no exílio; que o ajudou a tornar essa experiência uma oportunidade de refletir criticamente sobre outros contextos e a desenvolver suas reflexões e propostas. Além disso, Elza se preocupava em tornar o ambiente familiar mesmo estando em outros países, tentando compensar as dificuldades da família em se adaptar a uma nova vida (FREIRE, 1992). Em Por uma Pedagogia da Pergunta, Freire ressalta que "Elza e eu sempre nos esforçamos para que a nossa saudade do Brasil jamais se constituísse numa espécie de doença sentimentalista" (FREIRE; FAUNDEZ, 1985, p. 32). Foi também leitora atenta e colaboradora de Freire em seus escritos, havendo sempre em seus livros agradecimentos a Elza (FREIRE, 1992). Na Pedagogia do Oprimido há um afetuoso agradecimento a Elza "de modo geral, nossa primeira leitora, por sua compreensão e estímulos constantes a nosso trabalho que também é seu” (FREIRE, 1978, p. 25). 


\subsection{O exílio: o início de sua experiência internacional}

Em consequência do golpe militar de março de 1964 no Brasil, Freire teve seus direitos políticos cassados e perdeu seu emprego. Em 14 de abril de 1964, o Programa Nacional de Alfabetização, que tinha sido inaugurado alguns meses antes, foi extinto por decreto, sob a alegação de que o material empregado numa campanha de alfabetização não transmitia ideias democráticas e nem preservaria as instituições e tradições do povo. Freire teve então seus direitos políticos cassados e foi preso em 16 de junho. Ele passaria mais de vinte dias preso numa pequena cela em Recife e mais cinquenta dias em Olinda (KINKERDALL, 2010). Freire foi interrogado, sendo acusado de querer desencadear uma "revolução pacífica". Ele procurou enfatizar as raízes católicas de seu pensamento e a tentativa de promover uma mentalidade aberta, sendo libertado em setembro, mas novamente interrogado outras vezes no Rio de Janeiro. Antecipando sua prisão, pediu asilo político à embaixada da Bolívia e depois de passar mais de um mês na embaixada partiu para Bolívia esperando trabalhar para o Ministério de Educação (KINKERDALL, 2010).

Segundo Kinkerdall (2010, p. 60)

For Freire, the coup meant more than a decade and a half of exile, which pained him greatly. But for all the personal anguish that it caused him and his family, it also created new opportunities that made him into first a hemispheric and then an international figure. ${ }^{i}$

\subsection{Mudança no projeto de vida: o exílio e as possibilidades que se abriram}

A experiência internacional de Freire inicia-se com seu exílio político, depois do golpe militar de 1964, quando muitos intelectuais e professores de Esquerda foram presos e exilados por causa da censura e perseguição política. Para um homem que nunca havia deixado o Brasil, a experiência de viver no exílio foi particularmente difícil, principalmente no início, quando viveu na Bolívia e posteriormente no Chile.

Com base nos relatos feitos em Pedagogia da Esperança, Freire passa a se considerar andarilho do mundo quando começa a visitar outros países. Essa experiência de viver em outros países, em outros contextos culturais e econômicos, torna-se objeto de 
reflexão crítica do próprio Freire, ampliando seus referenciais de análise das diferentes situações de vida das classes trabalhadoras. O termo "realidade de empréstimo" é adotado a partir de uma conversa com Álvaro Vieira Pinto (outro exilado político):

$\mathrm{Na}$ verdade, um dos sérios problemas do exilado ou exiladai está em lidar, de corpo inteiro, com sentimentos, desejo, razão, recordação, conhecimentos acumulados, visões do mundo, com a tensão do hoje sendo vivido na realidade de empréstimo e o ontem, no contexto de origem, de que chegou carregado de marcas fundamentais. No fundo, como preservar sua identidade na relação entre ocupação indispensável no novo contexto e a pré-ocupação em que o contexto de origem deve constituir-se. Como lidar com a saudade sem permitir que ela vire nostalgia. Como inventar novas formas de viver e conviver numa cotidianidade estranha, superando assim ou reorientando uma compreensível tendência do exilado ou da exilada de, não podendo deixar de tomar, pelo menos por largo tempo, seu contexto de origem como referência, considerá-lo sempre melhor do que o de empréstimo. Às vezes, é melhor mesmo, mas nem sempre o é.

No fundo é muito difícil viver no exílio, conviver com todas as saudades diferentes- a da cidade, a do país, a das gentes, a de uma certa esquina, a da comida-, conviver com a saudade e educá-la também (FREIRE, 1992, p. $34)$.

Com base nos comentários de Álvaro Vieira Pinto e escrevendo sobre sua experiência, ele contrasta o que denominou de "contexto de origem", sua experiência brasileira, com o "contexto de empréstimo", sua experiência de viver fora do país. Freire toma o novo contexto como objeto de reflexão, mostrando como ele ampliou sua perspectiva levando a uma revisão de seus conceitos teóricos. A partir da experiência internacional começa a adquirir uma nova visão sobre o Brasil e, ao mesmo tempo, a estabelecer relações entre as experiências dos trabalhadores nesses diferentes contextos.

Em entrevista concedida a Chasin, Dantas e Madeira (1985, p. 27), Freire relembra que:

[...] descobri uma coisa no meu aprendizado, ao longo dos anos, eu descobri que o exílio, enquanto realidade de empréstimo, enquanto contexto secundário, só existe na medida em que é precedido pelo contexto original. Não é possível entender o exílio fora da inteligência da tensão existencial entre o contexto de origem, de onde a gente é expelido, e o contexto de empréstimo, aonde a gente chega. Então o exílio implica, de um lado, o transplante, mas de outro um implante. 
Apesar de inicialmente se sentir em um "contexto de empréstimo", Freire começa a se dar conta de que nesses países havia muitos traços culturais e problemas sociais em comum com o Brasil e se mostrou aberto a ampliar sua perspectiva de vida e trabalho a novas experiências, manteve-se sempre aberto a ouvir e a reconsiderar seus pontos de vista. Dessa forma, pode se integrar a novas realidades vivendo e tornando-se uma figura internacional.

Freire deixa a Bolívia e vai para o Chile por causa de problemas de saúde e por ter recebido novas propostas de trabalho.

\subsection{Chile: a primeira experiência enriquecedora}

O exílio abriu assim novas oportunidades para ele. A experiência de Paulo Freire no Chile, na alfabetização de adultos, de 1964 a 1969, representou um período muito frutífero em sua vida. Essa experiência foi tão importante como foi o período anterior no Brasil, pois foi durante o exílio no Chile que ele se tornou uma figura importante na América Latina. Em suas próprias palavras:

Cheguei ao Chile de corpo inteiro. Paixão, saudade, tristeza, esperança, desejo, sonhos rasgados, mas não desfeitos, ofensas, saberes acumulados, nas tramas inúmeras vividas, disponibilidade à vida, temores, receios, dúvidas, vontade de viver e de amar. Esperança sobretudo. [...] Somente nos meados de janeiro de 1965 nos encontramos de novo. Elza, as três filhas e os dois filhos, trazendo consigo também seus espantos, suas dúvidas, suas esperanças, seus medos, seus saberes feitos e fazendo-se recomeçarem comigo vida nova em terra estranha. Terra estranha a que fomos nos dando de tal forma e que ia nos recendo de tal maneira que a estranheza foi virando camaradagem, amizade, fraternidade. De repente, saudosos do Brasil, queríamos um bem especial ao Chile que nos ensinou América Latina de modo jamais por nós imaginado. (FREIRE, 1992, p. 35-36)

E em seguida:

$\mathrm{O}$ respeito às diferenças culturais, o respeito ao contexto a que se chega, acrítica à "invasão cultural", à sectarização e a defesa da radicalidade de que falo na Pedagogia do Oprimido, tudo isso é algo que, tendo começado a ser experimentado antes no Brasil e cujo saber trouxera comigo para o exílio, na memória do meu próprio corpo, foi intensamente, rigorosamente vivido por mim nos meus anos de Chile (FREIRE, 1992, p. 44).

No Chile, Freire trabalhou no Instituto de Capacitación e Investigación em Reforma Agrária (ICIRA) no seu terceiro ano de permanência no país. Nessa época, decidiu escrever e 
discutir os textos sobre os temas que seriam abordados nos encontros de capacitação. Além de escrever, tinha o hábito de discuti-los com dois amigos com quem trabalhava no ICIRA Marcela Gajardo, chilena atualmente professora da Faculdade Latino-Americana de Ciências Sociais; e José Luiz Fiori, brasileiro, sociólogo, atualmente professor da Universidade Federal do Rio de Janeiro (UFRJ). Essa troca de ideias foi essencial para suas reflexões, compartilhando experiências e aprofundando suas análises com interlocutores engajados no mesmo contexto. Isso certamente marcou sua posição quanto à importância do diálogo na experiência pedagógica que encontramos em suas obras posteriores.

Com eles debati vários momentos da Pedagogia do Oprimido ainda em processo de redação. Não tenho por que negar o bem que a amizade de ambos me fez e a contribuição que a inteligência arguta deles me trouxe (FREIRE, 1992, p. 53).

Freire explica que sua passagem pelo ICIRA possibilitou, pelo seu convívio com as equipes técnicas, sua rica experiência com um grande número de comunidades camponesas por todo o país, além de viver a atmosfera histórico-política da época. Isso fez com que ele aprofundasse hipóteses, tornando mais claras suas posições, redimensionando assim seu trabalho com base nessas novas experiências.

Foi vivendo a intensidade da experiência da sociedade chilena, da minha experiência, que me fazia re-pensar sempre a experiência brasileira, cuja memória viva trouxera comigo para o exílio, que escrevi a Pedagogia do oprimido entre 1967 e 1968 (FREIRE, 1992, p. 53).

Esta época no Chile é considerada muito importante no desenvolvimento de seu pensamento. Além de ter desenvolvido um dos seus trabalhos mais marcantes no ICIRA, neste período escreveu seus livros mais famosos (dentre eles Educação como Prática da Liberdade, Pedagogia do Oprimido, Extensão e Comunicação, Ação Cultural para a Liberdade) e elaborou os conceitos básicos de seu pensamento político-pedagógico (educação bancária, educação libertadora, cultura do silêncio, educação dialógica, entre outros). No trabalho de campo com campesinos em assentamento próximo à cidade de Santiago, Freire articulou estudo e pesquisa sobre educação de adultos ampliando suas experiências com os trabalhadores no Brasil. Essas duas experiências são relatadas no livro Pedagogia do 
Oprimido. Por essas razões, o período do Chile foi extremamente profícuo para a internacionalização de seu pensamento.

\subsection{Estados Unidos: descobrindo pontos em comum}

Freire levou um ano ou mais falando sobre o livro PO com amigos e discutindo em cursos que dava. Nesse período que podemos denominar de "oralidade do livro", recebeu o primeiro convite para visitar os Estados Unidos, em 1967, tendo sido convidado para visitar Nova York pelo Padre Joseph Fitzpatrick e pelo Monsenhor Robert Fox. Essa visita foi proposta pelo importante pedagogo Ivan Illich ${ }^{\mathrm{iii}}$, que conhecia os dois religiosos e achou que seria importante para eles o contato com Freire. Com efeito, para Freire essa visita foi extremamente importante, pois pode observar o trabalho que esses religiosos realizavam com os imigrantes porto-riquenhos e com os negros, que eram grupos discriminados. Ele viu que havia muita semelhança entre esse trabalho e o que ele desenvolvera no Brasil. De volta ao Chile, Freire continuou o que chamou fase de gestação da PO, começando a escrever ideias em fichas para desenvolver reflexões mais elaboradas. Depois de certo tempo, as "fichas de ideias" terminavam por tornarem-se fichas geradoras de novas ideias e de outros temas. A partir desse trabalho artesanal de reflexão, de revisão e de aprofundamento de suas próprias ideias, em julho de 1967, Freire escreve os três primeiros capítulos da PO. Tendo terminado de datilografar o texto, entrega ao seu grande amigo que estava também no Chile, Ernani Maria Fiori e lhe pede para que escreva o prefácio. No mesmo dia em que Fiori entregou de volta o texto com o prefácio, Freire resolve deixar o texto "descansar" por mais dois meses, quando resolve então escrever um capítulo a mais, o quarto capítulo.

Mesmo sabendo que o livro não poderia ser editado no Brasil, Freire envia o texto datilografado para Fernando Gasparian, diretor da Editora Paz e Terra. Nessa época, em 1969, quando a situação no Chile estava se tornando incômoda, Freire recebeu quase ao mesmo tempo ofertas para ensinar na Universidade de Harvard (Harvard University) e para trabalhar no Conselho Mundial de Igrejas (World Council of Churches, WCC), em Genebra. O teórico do desenvolvimento Denis Goulet foi responsável pelo convite para Harvard. Freire, anos mais tarde, descreveu sua decisão de aceitar ir aos Estados Unidos (por um tempo menor do que lhe foi oferecido) e depois aceitar o trabalho no Conselho. Assim, ele 
habilmente soube aproveitar as duas oportunidades que se abriram, por considerar essas duas novas experiências relevantes para o desenvolvimento de suas propostas. Em diálogo com Antonio Faundez, Freire conta:

Um caminho, Antonio, que descobri e que outros exilados também descobriram, foi exatamente o de ter o meu contexto de origem como permanente preocupação, sem que esta posição, porém, fosse assumida como pura psicoterapia. Por outro lado, perseguir um certo nível de inserção afetiva, emocional e intelectual no contexto de empréstimo. E, se quando possível, a partir dele, nos estender, com suficiente clareza política, a outros contextos que se abrissem a nós como áreas de ação. Por isso é que, quando ainda no Chile, recebi o convite da Universidade de Harvard a três ou quatro dias depois do convite do Conselho Mundial de Igrejas (Harvard me convidava para dois ou três anos, a partir de 69, e o Conselho Mundial de Igrejas também, com diferença de meses apenas para começar), propus a Harvard ficar nela até começos de fevereiro de 1970 e ao Conselho Mundial de Igrejas começar meu contrato em meados de fevereiro daquele ano (FREIRE, 1985, p. 21).

Resolveu então aceitar o convite para lecionar em Harvard. Durante esse período publicou dois textos no periódico de grande prestígio e influência Harvard Educational Review. Essas publicações em língua inglesa em um periódico de renome trouxeram enorme repercussão ao seu trabalho, marcando o início de seu reconhecimento como intelectual no meio acadêmico internacional.

\subsection{Conselho Mundial de Igrejas (Genebra/ Suíça): novas realidades e novos desafios}

Após sua experiência em Harvard, Freire diz:

Considerava altamente importante para mim, intelectual brasileiro no exílio, uma passagem ainda que rápida pelo centro do poder capitalista. Precisava ver de perto, como disse a companheiros brasileiros e chilenos de que então me despedia em Santiago, o "bicho" em sua toca. Mas, por outro lado, estava, já na época, absolutamente convencido de quão útil e fundamental seria a mim correr o mundo, expor-me a contextos diversos, aprender das experiências de outros, rever-me nas diferenças culturais. E isto o Conselho me oferecia indiscutivelmente mais que qualquer universidade (FREIRE, 1985, p. 21). 
A universidade, no fundo, por boa que fosse, por famosa que fosse, por grande que fosse, significava a oportunidade de trabalhar, em semestres, com grupos de estudantes, vinte, trinta. O Conselho Mundial de Igrejas me oferecia uma cátedra mundial, me oferecia não o espaço de uma universidade, mas o espaço do mundo, me oferecia o contexto maior do mundo, as suas diferentes experiências, a visão de algumas de suas tragédias, de suas misérias, de suas desgraças, mas também de alguns de seus momentos de beleza- a libertação dos povos africanos, o da revolução nicaraguense, o da revolução de Grenada (FREIRE, 1985, p. 22).

O trabalho em Genebra trouxe novas experiências e novos desafios, uma vez que não se tratava mais de lecionar apenas, mas de participar de projetos de política educacional em países em desenvolvimento, levando-o a conhecer novas propostas e novas práticas. De acordo com Andreola e Ribeiro (2005, p. 107), “o trabalho no Conselho Mundial de Igrejas abriu para Freire um espaço sem limites para projetos de ação educativa em todos os continentes, mas sobretudo por sua opção política em vários países africanos que estavam se libertando do colonialismo". Sua atuação no Conselho permitir que sua proposta libertadora e sua obra adquirissem dimensões universais tornando Freire uma figura amplamente reconhecida internacionalmente.

Foi palmilhando este contexto enorme que o Conselho Mundial me oferecia que me fui tornando um andarilho do óbvio. E foi andarilhando pelo mundo, foi andando pela África, foi andando pela Ásia, pela Austrália, Nova Zelândia, pelas ilhas do Pacífico sul; foi andando a América Latina toda, o Caribe, a América do Norte, A Europa, foi caminhando por esses pedaços do mundo, como exilado, que pude compreender melhor o meu país. Foi vendo-o de longe, foi tomando distancia dele que eu entendi melhor a mim mesmo. Foi me confrontando com o diferente de mim que descobri mais facilmente a minha própria identidade (FREIRE, 1985, p. 22).

\section{TORNANDO-SE UM AUTOR INTERNACIONAL E AMPLIANDO A PERSPECTIVA INTERNACIONAL}

A partir dessas experiências profissionais em contextos internacionais, Paulo Freire amplia sua reflexão teórica sobre os problemas da educação e da perspectiva da opressão nesses diferentes e é convidado a publicar em língua inglesa. A partir daí sua influência se consolida e ele pôde expandir dos seus contextos de atuação profissional, sendo lido por autores que tinham uma perspectiva crítica, principalmente na área do currículo, 
principalmente nos Estados Unidos. A publicação em Inglês de suas obras, vinculada à relevância e originalidade da forma e conteúdo de suas reflexões, contribuíram para que ele fosse se tornando um autor internacional.

\subsection{A publicação da Pedagogia do Oprimido em língua inglesa}

Freire torna-se um autor internacional a partir, principalmente, da publicação de três documentos: (I) suas palestras em Harvard publicadas em dois artigos, na Harvard Educational Review, nos números de maio e agosto de 1970; (II) esses dois artigos dão origem a uma monografia, publicada pelo Center for the Study of Development and Social Change (Centro para o Estudo do Desenvolvimento e Mudança Social) em livro intitulado Cultural Action for Freedom, em Cambridge, Massachusetts, em setembro de 1970; (III) a obra Pedagogia do Oprimido foi inicialmente publicada em inglês, em 1970, pela editora Herder and Herder, em Nova York (FREIRE, 1992) e somente mais tarde em português, no Brasil, em função da censura.

A Pedagogia do Oprimido, sua principal obra, tem suas raízes nas experiências de vida de Paulo Freire. Os temas abordados foram educação bancária e libertadora, método dialógico; e o modo como desenvolveu a análise desses temas e suas propostas reflete diretamente sua experiência do exílio, inicialmente, e posteriormente como professor e pesquisador nos Estados Unidos.

Em Pedagogia da Esperança, Freire fala sobre o contexto da época em que aparece o livro PO:

O livro apareceu numa fase histórica cheia de intensa inquietação. Os movimentos sociais na Europa, nos Estados Unidos, na América Latina, em cada espaço-tempo com suas características próprias. A luta contra a discriminação sexual, racial, cultural, de classe, a luta em defesa do ambiente, os verdes, na Europa. Os golpes de estado com a nova face, na América Latina, e seus governos militares que se alongaram da década anterior. [...] As guerrilhas na América Latina; as comunidades de base, os movimentos de libertação na África, a independência das ex-colônias portuguesas, a luta na Namíbia, Amílcar Cabral, Julius Nyetere, sua liderança na África e sua repercussão fora da África. [...] As lutas político-sindicais e pedagógicosindicais, todas obviamente políticas, sobretudo na Itália. [...] A guerra no Vietnã e a reação no interior dos Estados Unidos. 


\begin{abstract}
A luta pelos direitos civis e o transbordamento do clima político-cultural dos anos 60, naquele país, para a década de 70 .

Estas eram, com um sem-número de implicações e de desdobramentos, algumas das tramas históricas sociais, culturais, políticas, ideológicas que tinham a ver, de um lado, com a curiosidade que o livro despertava, de outro, com a leitura que dele se faria também, de sua aceitação. De sua recusa. De crítica a ele feitas (FREIRE, 1992, p. 121).
\end{abstract}

3.1.1 Os diferentes prefácios da obra

As diferentes edições de Pedagogia do Oprimido no Brasil são apresentadas a convite de Paulo Freire por prefácio escrito por Ernani Maria Fiori, intitulado Aprenda a Dizer sua Palavra. Nesse prefácio, Fiori resume os principais aspectos da obra e ressalta a importância de sua proposta inovadora. Fiori foi catedrático de História da Filosofia da Universidade Federal do Rio Grande do Sul e era amigo pessoal de Freire. Com o movimento de 1964, devido à perseguição política, assim como Freire, exilou-se no Chile, onde atuou na Universidade Católica (da qual chegou a Vice-Reitor).

A edição em Língua Portuguesa publicada no Brasil em seguida contém o prefácio escrito por Paulo Freire e intitulado Primeiras Palavras, retomando sua experiência inicial e refletindo sobre a concepção da obra.

Já nas edições em Língua Inglesa publicadas nos Estados Unidos há um Foreword, escrito por Richard Shaull ${ }^{\text {iv }}$, sendo que o que no Brasil aparece como Primeiras Palavras, escrito por Paulo Freire, nos Estados Unidos denominou-se simplesmente Preface (Prefácio). Na publicação comemorativa do aniversário da $30^{\text {a }}$ edição da obra em Língua Inglesa, além do Foreword e do Preface, há uma Introduction to the Anniversary Edition, escrita por Donaldo Macedo ${ }^{\mathrm{v}}$ por ocasião dos trinta anos da publicação, assim como fez mais recentemente na publicação comemorativa dos 50 anos.

É interessante constatar os diferentes enfoques dados nas introduções em Língua Inglesa. Na primeira edição (publicada antes da edição em português), Richard Shaull introduz a obra de Freire destacando que o autor traz contribuições importantes para a América Latina que são também essenciais para a educação estadunidense:

In this country, we are gradually becoming aware of the work of Paulo Freire, but thus far we have thought of it primarily in terms of its contribution to the education of illiterate adults in the Third World. If, 
however, we have a closer look, we may discover that his methodology as well as his educational philosophy are as important for us as for the dispossessed in Latin America... For this reason, I consider the publication of Pedagogy of the Oppressed in an English edition to be something of an event (SHAULL, 2011, p. 29). ${ }^{\mathrm{vi}}$

Outro prefácio importante é de Donaldo Macedo, escrito em 2000. Passados trinta anos da publicação da primeira edição, Paulo Freire já se tornara internacionalmente conhecido e sua obra e propostas já haviam sido apropriadas e utilizadas em diferentes lugares. É nesse contexto que se situam as reflexões de Macedo ao comentar várias interpretações equivocadas da filosofia e proposta freireana, que transformam a proposta de educação dialógica em apenas um método de alfabetização, rebatendo algumas críticas feitas ao trabalho de Freire:

Unfortunately, in the United States, many educators who claim to be Freirean in their pedagogical orientation mistakenly transform Freire's notion of dialogue in a method, thus losing sight of the fact that the fundamental goal of dialogical teaching is to create a process of learning and knowing that invariably involves theorizing about the experiences shared in the dialogue process. Some strands of critical pedagogy engage in an overdose of experiential celebration that offers a reductionistic view of identity and experience removed from the problematic of power, agency, and history, By overindulging in the legacy and importance of their respective voices and experiences, these educators often fail to move beyond a notion of difference structured in polarizing binarisms and uncritical appeals to the discourse of experience. [...] At the same time, educators who misinterpret Freire's notion of dialogical teaching into a method also refuse to link experiences to the politics of culture and critical democracy, thus reducing their pedagogy to a form of middle-class narcissism. This creates, on the one hand, the transformation of dialogical teaching into a method invoking conversation that provides participants with a group-therapy space for stating their grievances. On the other hand, it offers the teacher as facilitators a safe pedagogy zone to deal with his or her guilt (MACEDO, 2011, p. 17). ${ }^{\text {vii }}$

Seguindo os diferentes prefácios, nas diversas traduções, nos diversos idiomas, Freire registra seu próprio prefácio, intitulado Primeiras Palavras. No Brasil, o texto se encerra com o agradecimento à Elza, sua primeira esposa e leitora, e a todos que o auxiliaram, tendo data o outono de 1968, e o local onde Paulo Freire conclui sua obra $(\text { Santiago, no Chile })^{\text {viii }}$. 
As páginas que se seguem e que propomos como uma introdução à Pedagogia do Oprimido são o resultado de nossas observações nestes cinco anos de exílio. Observações que se vêm juntando às que fizemos no Brasil, nos vários setores em que tivemos oportunidade de exercer atividades educativas (FREIRE, 1970, p. 19).

[...] As afirmações que fazemos neste ensaio, não são, de um lado, fruto de devaneios intelectuais, nem tampouco, de outro, resultam, apenas, de leituras, por mais importantes que nos tenham sido estas. Estão sempre ancoradas, como sugerimos no início dessas páginas, em situações concretas. Expressam reações de proletários, camponeses ou urbanos, e de homens de classe média, que vimos observando, direta ou indiretamente, em nosso trabalho educativo. Nossa intenção é continuar com estas observações para retificar ou ratificar em estudos posteriores, pontos afirmados neste ensaio. Ensaio que, provavelmente, irá provocar em alguns de seus possíveis leitores, reações sectárias (FREIRE, 1970, p. 21).

[...] ensaio puramente aproximativo, um trabalho para homens radicais. Cristãos ou marxistas, ainda que discordando de nossas posições, em grande parte, em parte ou em sua totalidade, estes, estamos certos, poderão chegar ao fim do texto (FREIRE, 1970, p. 21.)

\subsection{O impacto da Pedagogia do Oprimido no contexto norte-americano}

O próprio Freire faz uma análise do impacto do livro:

De fato, aparecida em Nova York, em setembro de 1970, a Pedagogia começou imediatamente a ser traduzida a várias línguas, gerando curiosidades e críticas favoráveis, umas; desfavoráveis, outras. Até 1974, o livro tinha sido traduzido ao espanhol, ao italiano, ao francês, ao alemão, ao holandês e ao sueco e tinha sua publicação em Londres, pela Penguin Books. Esta edição estendeu a Pedagogia à África, à Ásia e à Oceania (FREIRE, 1992, p. 120).

O livro Pedagogia do Oprimido exerceu uma grande influência nos campos teórico e prático dos estudos curriculares. Quando viveu nos Estados Unidos, Freire passou a ter contato com autores da assim chamada pedagogia crítica, como Giroux (2001), McLaren

(2001) e Ira Shor (1986), entre outros, que mais tarde incorporaram em suas análises políticopedagógicas vários conceitos freireanos, sempre reconhecendo a importância do educador brasileiro em seu pensamento.

Freire tornou-se um autor internacional quando sua obra Pedagogia do Oprimido foi publicada em Inglês (Pedagogy of the Oppressed) e lida amplamente no meio educacional e especificamente pelos teóricos na área de estudos curriculares nos Estados Unidos e na Inglaterra, sendo depois traduzida em muitas outras línguas em vários países pelo mundo 
afora. Esses autores estrangeiros encontraram na obra de Freire subsídios teóricos e práticos para reconceituar o campo do currículo (1970-1979) que - de acordo com Pinar, Reynolds, Slattery e Taubman (1995) - estava sendo considerado, naquele momento, tradicional, tecnicista com finalidades específicas de organização do trabalho pedagógico nas escolas sem questionar o conhecimento que era ensinado, como era ensinado e por que era ensinado. Vários intelectuais norte-americanos, canadenses e de várias outras nacionalidades passam a incorporar em suas análises alguns conceitos desenvolvidos por Freire, dentre os quais o aspecto político inerente ao processo de educação, e diante disso a necessidade de uma pedagogia crítica e o método dialógico estão entre os principais.

A obra de Freire permitiu aos teóricos na década de 1970 ter uma referência para se contrapor ao princípio de correspondência de Bowles e Gintis, ao processo de reprodução cultural e social de Bourdieu e Passeron, e aos princípios teóricos de Althusser. Assim, buscam alternativas teóricas e práticas que ultrapassassem o imobilismo decorrente das teorias da reprodução trazendo para a discussão conceitos como emancipação, transformação e resistência. Esses conceitos que vão ser ampliados pelos teóricos da área de currículo serviram de base para a constituição de um paradigma crítico que pudesse se contrapor ao tradicional. A emancipação será um dos objetivos da ação e educação politizadas. Em relação ao processo pedagógico, a utilização do método dialógico irá permitir às pessoas tomarem consciência do papel do poder e do controle exercido pelas instituições e estruturas sociais, sendo que desta forma podem se tornar emancipadas e libertadas desse mesmo poder. Os conceitos de educação libertadora e ação cultural vão fornecer a base para pensar possibilidades emancipadoras a partir da pedagogia e do currículo que estavam ausentes nas teorias da reprodução. Os conceitos de "educação libertadora" em oposição à "educação bancária" e a sua concepção de conhecimento ativo e dialético ajudam aos teóricos críticos como Giroux e McLaren a desenvolver uma perspectiva de currículo que contestasse os modelos dominantes de natureza puramente tecnicista (SILVA, 2002).

Giroux desenvolve o conceito de intelectual transformador a partir de Gramsci e Freire. Tendo como base a noção de "intelectual orgânico" de Gramsci, Giroux propõe que os professores sejam encarados como "intelectuais transformadores", isto é, pessoas ativamente envolvidas nas atividades de crítica e questionamento, ao serviço da transformação e $===$ 


\section{e-Curriculum}

emancipação e não como técnicos e burocratas, considerados apenas como implementadores de políticas. A categoria de intelectual tem sido utilizada de várias maneiras pelos educadores críticos, pois ela pode oferecer uma base teórica para examinar-se a atividade docente como uma forma de trabalho intelectual, em contraste com sua definição em termos puramente técnicos. Por outro lado, pode também esclarecer os tipos de condições ideológicas e práticas necessárias para que os professores funcionem como intelectuais e, além disso, tem ajudado a esclarecer o papel que professores desempenham na produção e legitimação de interesses políticos, econômicos e sociais variados através das pedagogias por eles endossadas e utilizadas (SILVA, 2002). Esse conceito tem acompanhado Giroux em toda a sua obra, inclusive em seus textos mais recentes, onde ele analisa o impacto da mídia nos acontecimentos de 11 de setembro.

O conceito de educação dialógica de Freire continuou a ser usado pelos teóricos críticos argumentando que na escola, e por meio do currículo, os estudantes devam ter a oportunidade de desenvolver o exercício permanente da discussão e da participação, levando ao questionamento dos pressupostos do senso comum da vida social, revendo preconceitos, estereótipos e atitudes discriminatórias, assim como revendo a construção de representações do mundo e da sociedade. Questionando, em última análise, as condições que geram as injustiças sociais e buscando alternativas para acabar com elas.

McLaren tem afirmado que a obra de Freire tem sido "a força motriz por trás dos esforços norte-americanos para desenvolver a pedagogia crítica” (McLAREN, 2001, p. 185). Essa pedagogia crítica, para ele, consiste em uma forma de refletir, negociar e transformar a relação entre ensino em sala de aula, incluindo também a produção do conhecimento, o questionamento das estruturas institucionais das escolas e as relações como também as relações sociais e materiais na comunidade, sociedade e Estado-Nação. A proposta freireana até os tempos atuais vem ajudando educadores progressistas a viabilizar estruturas curriculares, projetos políticos contrários ao preconceito racial e sexual. McLaren também ressaltou que muitos críticos da abordagem freireana desaprovam sua visão - muitas das vezes considerada idealista ou utópica. Seus defensores têm se queixado que a pedagogia crítica tem sido empregada de forma domesticada e reduzida a abordagens de aprendizado dirigidas aos alunos e às alunas, desprovida de crítica social (como Donaldo Macedo 
mencionou no prefácio da publicação da $30^{\text {a }}$ edição em Língua Inglesa da Pedagogia do Oprimido).

McLaren também nos lembra (2001, p. 190) que o trabalho de Freire precisa ser "reinventado" nos contextos em que os leitores se encontram, admitindo, portanto, uma "tradução" específica de acordo com o contexto, cruzando fronteiras geográficas, geopolíticas e culturais, como o próprio Freire nos disse.

Freire também adquiriu uma perspectiva internacional através das críticas que lhe foram feitas pelo movimento feminista nos Estados Unidos. No contexto americano, ele foi criticado pelas feministas por usar, em sua obra, no período inicial dos seus escritos, o que elas chamaram de "linguagem sexista e machista". Freire recebeu essas críticas com humildade, reconhecendo o seu desconhecimento dessa problemática que para ele, até aquele momento, era desconhecida. Freire explicou que, como era "um homem do Nordeste do Brasil", fazia parte de uma sociedade tradicionalmente patriarcal e não tinha consciência, ele mesmo, da linguagem sexista que havia empregado em sua obra ${ }^{\mathrm{ix}}$. Reconhecendo que isso era um ponto importante, pediu a seu tradutor que revisasse a tradução de sua obra para o Inglês. Viu, portanto, que o conceito de opressão poderia ser empregado em sentido amplo incluindo relações de gênero. Dessa forma, ao reconhecer a problemática de gênero, Freire adquiriu pessoalmente uma nova perspectiva sobre formas de opressão e deu ao seu trabalho político uma dimensão internacional.

Por ocasião dos 50 anos da publicação da PO em Língua Inglesa, foi feita uma edição comemorativa com introdução de Donaldo Macedo.

Na Introdução da edição da Pedagogia do Oprimido, 50ª Edição de aniversário, Donaldo Macedo ressalta que

[...] Freire's major goal in Pedagogy of the Oppressed was not to propose an innovative methodology (which would be antithetical to his critique of formulaic models of education) but to launch the development of an emancipatory pedagogical process that invites and challenges students, through critical literacies, to learn how to negociate the world in which they find themselves, in a thoughtful and critically reflective manner, so as to expose and engage the tensions and contracditions inherent in the ongoing relations between the opressor and the oppressed. Thus, the central goal of Freire's Pedagogy of the Oppressed is to awaken in the oppressed the knowledge, creativity, and constant critical reflective capacities necessary to unveil, desmystify, and understand the power relations responsible for their 
oppressed marginalization and, through this recognition, begin a project of liberation through praxis which, invariably, requires consistent, neverending critical reflection and action (MACEDO apud FREIRE, 2018, p. 2).

...Freire has to be viewed and understood beyond his literacy instructional methods by critically apprehending his notion of conscientization $-a$ concept that is often misunderstood even by critical educators who claim to be Freirian, and conveniently dismissed by educators whose interest is to appropriate Freire's major theoretical goal thus reducing him to a mere instructional methodologist (MACEDO apud FREIRE, 2018, p. 3).

Assim, Donaldo Macedo reestabelece a importância de se ver a proposta freireana dentro de uma concepção filosófica e política mais ampla e não uma metodologia de ensino.

\section{CONSIDERAÇÕES FINAIS}

Retomando nossas questões de pesquisa: Por que Paulo Freire é considerado um autor internacional? Como ele influenciou o contexto internacional dos estudos curriculares inicialmente com a publicação da PO? Por outro lado, como sua experiência internacional no sentido de viver em outros países e ter contato com outros pesquisadores, influenciou o seu próprio trabalho? Particularmente importante é discutir como e porque Paulo Freire tornou-se um autor com influência internacional se ele inicialmente escreveu sobre seu contexto local.

Como mostramos neste trabalho, Freire adquire uma perspectiva internacional quando, na condição de exilado, passa a viver em outros países (inicialmente, Bolívia, depois Chile e Estados Unidos), e a vincular sua experiência como professor alfabetizador e pensador no Brasil com outras experiências em outros contextos, estabelecendo pontos em comum entre sua experiência e a experiência de trabalhadores, sindicalistas e religiosos que desenvolviam trabalhos com populações pobres, marginalizadas e excluídas das sociedades com as quais teve contato. No caso de trabalhadores rurais e sindicalistas na Bolívia e Chile e no caso de imigrantes latinos, negros e pobres nos Estados Unidos, na cidade de Nova York, Freire reconhece em suas situações de vida o conceito de opressão e a possibilidade de, por meio da educação/alfabetização crítica, chegar à emancipação, à libertação. Assim, a partir do reconhecimento de realidades semelhantes à sua realidade nordestina, brasileira, Freire pode trocar experiências e reflexões com trabalhadores e intelectuais, ampliando sua perspectiva e adquirindo uma dimensão internacional. Essa perspectiva foi amplamente enriquecida quando 
Freire aceita um cargo no Conselho Mundial de Igrejas e passa a viajar para dar apoio e desenvolver trabalhos de alfabetização/educação nas colônias africanas que haviam se libertado dos colonizadores pouco antes. Nessas viagens, Freire conversou com líderes políticos, trabalhadores rurais, sindicalistas, ativistas que oportunizaram trocas de experiências importantes para que ele fosse redimensionando seu pensamento, sua proposta política e o ensino dialógico.

Podemos concluir afirmando que Freire traçou um projeto, mas sua vida foi modificando esse projeto e ele conseguiu tirar proveito disso, inclusive das adversidades como o período do exílio. Assim, ele não só adquiriu uma perspectiva internacional com sua vivência em países estrangeiros por uma troca rica de experiências como também tornou-se um autor internacional, que tendo recebido críticas, soube incorporar aspectos que deram a sua obra prestígio e visibilidade, vindo a ser internacionalmente reconhecida. $\mathrm{O}$ exílio foi uma experiência penosa, porém, Freire conseguiu transformá-la em abertura de novas possibilidades para aprender. O seu capital cultural ampliou-se a partir de outras vivências em outros contextos. Dessa forma, foi aprofundando sua experiência internacional e pode se conceber como "cidadão do mundo", permitindo estabelecer relações entre a realidade brasileira e a de outros países, como Bolívia e Chile, com problemas semelhantes, encontrando outros intelectuais e agentes sociais cujas preocupações se aproximavam das suas e ampliando sua experiência como pensador social que influenciou o campo dos estudos curriculares. Paulo Freire torna-se, então, uma das mais importantes referências na educação não só com sua obra, mas também com sua maneira de ver o mundo e de encarar a vida. 


\section{REFERÊNCIAS}

ANDREOLA, Balduíno A. e RIBEIRO, Mário Bueno. Paulo Freire no Conselho Mundial das Igrejas em Genebra. Estudos Teológicos, v.45, n.2, p.107-116, 2005.

ANDREOLA, Balduíno A. Paulo Freire e Ernani Fiori: uma longa parceria políticopedagógica. Revista Eletrônica do Mestrado em Educação Ambiental. Universidade do Rio Grande do Sul- FURG, p.6-24, junho 2017.

CHASIN, J. ; DANTAS, Rui Gomes e MADEIRA, Vicente. Entrevista: Caminhos de Paulo Freire. Ensaio, Publicação Editora Ensaio Ltda, S.Paulo, no14, 1985.

FREIRE, Ana Maria Araujo. Paulo Freire: uma história de vida. Indaiatuba, S.P.: Villa das Letras, 2006.

FREIRE, Paulo. Pedagogia do Oprimido. S. Paulo: Ed. Paz e Terra, 5ª Ed., 1978.

FREIRE, Paulo. Pedagogia da Esperança. S.Paulo: Ed. Paz e Terra, 1992.

FREIRE, Paulo. Educação como Prática da Liberdade. $1^{\text {a }}$ Edição, Rio de Janeiro, Paz e Terra, 1967.

FREIRE, Paulo. Extensão ou Comunicação? , 3ª Edição, Rio de Janeiro, Paz e Terra, 1977.

FREIRE, Paulo. Ação Cultural para a Liberdade e outros escritos. 2aEdição, Rio de Janeiro, Paz e Terra, 1977.

FREIRE, Paulo e FAUNDEZ, Antonio. Pedagogia da Pergunta. Rio de Janeiro: Paz e Terra, 1995.

FREIRE, Paulo. Pedagogy of the Oppressed: 50th Anniversary Edition New York/London: Bloomsbury Academic, 2018.

GIROUX, Henry. Os professores como intelectuais: rumo a uma pedagogia crítica da aprendizagem.Porto Alegre: Artes Médicas, 1997.

GIROUX, Henry. Paulo Freire and the politics of postcolonialism. In McLAREN, Peter e LEONARD, Peter (Eds) Paulo Freire: a critical encounter. London/New York: Routledge. P.177-188, 1995.

GIROUX, Henry - Recordando o legado da Pedagogia do Oprimido.In FREIRE, Ana Maria Araujo (Org) A Pedagogia da Libertação em Paulo Freire. S.Paulo: Editora UNESP.p.113$117,2001$. 
KINKERDALL, Andrew J. Paulo Freire: the cold war politics of literacy. The University of North Carolina Press, 2010.

MACEDO, Donaldo. Introduction to the Anniversary Edition. In Pedagogy of the Oppressed $30^{\text {th }}$ Anniversary Edition.New York/London: Continuum International Publishing Group, 2011.pp 11-27.

McLAREN, Peter. Uma política da possibilidade: reflexões sobre a política educacional de Paulo Freire. In FREIRE, Ana Maria Araujo (Org) A Pedagogia da Libertação em Paulo Freire. S.Paulo: Editora UNESP.p.179-196, 2001.

PINAR, William F.; REYNOLDS; William M.; SLATTERY, Patrick e TAUBMAN, Peter M. Understanding Curriculum: an introduction to the study of historical and contemporary curriculum discourses. New York: Peter Lang Publishing, 1995.

SHAULL, Richard. Foreword. In Pedagogy of the Oppressed $30^{\text {th }}$ Anniversary Edition.New York/London: Continuum International Publishing Group, 2011. pp. 29-34.

SILVA, Tomaz Tadeu da. Documentos de Identidade: uma introdução às teorias do currículo.Belo Horizonte, Autêntica, 2002.

\section{Notas}

i "Para Freire, o golpe significou mais do que uma década e meia de exílio, que o magoou muito. Contudo, para além de toda angústia pessoal que isso causou a ele e sua família, também criou novas oportunidades que o tornaram uma figura conhecida regionalmente, no hemisfério sul e então, internacional"(tradução nossa)

ii Aqui Freire já usa o tipo de linguagem usada que leva em conta a igualdade dos gêneros. Na primeira publicação da Pedagogia do Oprimido Freire não utilizou este tipo de linguagem e por esta razão sofreu inúmeras críticas dos grupos feministas nos Estados Unidos. Depois disso procurou, em todas as suas publicações, levar em conta este tipo de linguagem.

iii Autor da obra "Sociedade sem escolas" (disponível para download em http://www.dominiopublico.gov.br/download/texto/me4673.pdf). A primeira edição foi publicada em 1971.

${ }^{\mathrm{iv}}$ Richard Shaull (1919-2002) foi um teólogo presbiteriano ecumênico estadunidense, reconhecido por suas contribuições ao desenvolvimento da gênese da teologia da libertação latino-americana.

${ }^{v}$ Donaldo Pereira Macedo é teórico crítico, linguista, e especialista cabo-verdiano em alfabetização, pedagogia crítica e estudos da educação multicultural. Macedo é professor de inglês e professor Emérito de Artes liberais e Educação na Universidade de Massachusets, Boston. Macedo foi tradutor de muitas das obras de Paulo Freire.

vi "Nesse país, tomamos paulatinamente ciência do trabalho de Paulo Freire, mas primordialmente pensamos em relação à sua contribuição aos analfabetos do Terceiro Mundo. Se, contudo, olharmos com maior atenção, podemos descobrir que sua metodologia, bem como sua filosofia educacional, são tão importantes para nós como para os despossuídos na América Latina (...) Por esta razão, eu considero que a publicação da Pedagogia do Oprimido, em edição em língua inglesa, deve ser considerada um evento.” (tradução nossa)

vii، Infelizmente, nos Estados Unidos, muitos educadores que se denominam Freireanos em sua orientação pedagogicamente, erroneamente transformam a noção de diálogo em Freire em um método, perdendo, então, de vista o fato de que o objetivo fundamental do ensino dialógico é criar um processo de aprendizagem e conhecimento que envolve invariavelmente teorizar sobre as experiências compartilhadas no processo dialógico. Algumas linhas da pedagogia crítica enfatizam excessivamente a celebração "experiencial" que oferece uma visão reducionista da identidade e da experiência removidas da problemática do poder, agência, e história. Ao 


\section{$e$-Curriculum}

Programa de Pós-Graduação em Educação: Currículo

supervalorizar o legado e a importância das suas respectivas vozes e experiências, esses educadores muitas vezes falham em ir além da noção de diferença estruturada polarizando binarismos e apelos acríticos ao discurso da experiência(...) Ao mesmo tempo, os educadores que tornam erroneamente a noção freireana de ensino dialógico em um método, também recusam conectar essas experiências políticas da cultura e democracia crítica, reduzindo então sua pedagogia a uma forma de narcisismo da classe média. Isso cria, por um lado, a transformação do ensino em um método que evoca uma conversação que provê aos participantes um espaço de terapia de grupo para expor suas queixas. Por outro lado, isso oferece os professores como facilitadores de uma zona pedagógica segura para lidar com a culpa [das pessoas de classe média] (...) (tradução nossa)

viii Nas edições publicadas nos Estados Unidos, além de agradecer à esposa Elza, Paulo Freire cita nominalmente pessoas que o ajudaram: João da Veiga Coutinho, Richard Shaull, Jim Lamb, Myra e Jovelino Ramos, Paulo de Tarso, Almino Affonso, Plínio Sampaio, Ernani Maria Fiori, Marcela Gajardo, José Luis Fiori, e João Zacarioti. Também não há data nem local. 